\title{
Making the EU "Risk Window" transparent: The normative foundations of the environmental risk assessment of GMOs
}

\author{
Karsten Klint JENSEN ${ }^{1, *}$, Christian GAMBORG ${ }^{2}$, Kathrine Hauge MADSEN ${ }^{3}$, Rikke Bagger JøRGENSEN ${ }^{4}$, \\ Martin Krayer von KRAUSS ${ }^{5}$, Anna Paldam FOLKER ${ }^{3}$ and Peter SANDøE ${ }^{3}$ \\ ${ }^{1}$ Centre for Bioethics and Risk Assessment, Department of Education, Philosophy and Rhetoric, University of Copenhagen, Njalsgade 80, \\ 2300 Copenhagen S, Denmark \\ ${ }^{2}$ Centre for Bioethics and Risk Assessment, Danish Forest and Landscape Research Institute, Hørsholm Kongevej 11, 2970 Hørsholm, \\ Denmark \\ ${ }^{3}$ Centre for Bioethics and Risk Assessment, Royal Veterinary and Agricultural University, Grønnegaardsvej 8, 1870 Frederiksberg C, \\ Denmark \\ ${ }^{4}$ Centre for Bioethics and Risk Assessment, Plant Environment Interactions, Plant Research Department, RIS $\emptyset$ National Laboratory, \\ Building 309, Frederiksborgvej 399, PO Box 49, 4000 Roskilde, Denmark \\ ${ }^{5}$ Centre for Bioethics and Risk Assessment, Environment and Resources, Technical University of Denmark, Bygningstorvet, Building 115, \\ 2800 Lyngby, Denmark
}

In Europe, there seems to be widespread, morally based scepticism about the use of GMOs in food production. In response to this scepticism, the revised EU directive 2001/18/EC on the deliberate release into the environment of genetically modified organisms stresses the importance of respecting ethical principles recognized in the Member States. However, the directive fails to reflect the critical role of value judgements in scientific risk assessment and any subsequent approval procedure. In this paper we argue that it is important to make all ethically relevant assumptions involved in the approval procedure transparent and thus available for public scrutiny. Mapping the value judgements that are made in an environmental risk assessment and approval procedure, we describe the political liberal nature of the EU legislation. We then look more closely at the prescriptions for environmental risk assessment and approval of GMOs outlined in the directive. An environmental risk assessment views the world through a "risk window" that only makes visible that which has been predefined as a relevant risk. The importance of the value judgements that define the risk window consists in limiting the information the risk assessment can provide. In the penultimate section of the paper, the significance of the risk window is demonstrated through a case study of the approval of glyphosate resistant fodder beets (Beta vulgaris L. ssp. vulgaris) in Denmark.

Keywords: ethics / EU legislation / familiarity / political liberalism / transparency / value judgements / risk window

\section{INTRODUCTION: THE IMPORTANCE OF TRANSPARENCY}

The cultivation of genetically modified plants in agriculture is currently the focus of strong scientific and commercial interest. However, GMOs have also prompted an intense public and political debate, particularly in Europe. Eurobarometer surveys (CEC, $1992 ; 1993 ; 1997$; 2000a) have consistently shown that the use of gene technology in agriculture and other areas

\footnotetext{
* Corresponding author:
}

Fax: +45 35328850; e-mail: kkjensen@hum.ku.dk of food production has a low level of support among the general public in Europe. Underlying this scepticism is a complex body of attitudes that has been summarized thus: "usefulness is a precondition of support for gene technology used outside the medical sphere. Furthermore people are prepared to accept a low level of risk as long as there is a perception of usefulness. However moral 
doubts act as a veto irrespective of views on usefulness and risk" (BEPCAG, 1997).

The Commission of the European Union (EU) hopes to restore public trust by tightening up the approval procedure for GMOs (CEC, 2000b). It has, as a result, revised EU legislation regarding the release and marketing of GMOs and issued a new directive 2001/18/ EC (CEC, 2001) on the deliberate release into the environment of genetically modified organisms. Unlike its forerunner 90/220/EEC (CEC, 1990), the revised directive explicitly invokes the "Precautionary Principle" (Preamble (8)). This development is manifest in, among other things, the introduction of time-restricted approvals (Article 15(4)) and requirements covering post-release monitoring (Article 19(3)). The revised directive also stresses that an environmental risk assessment must comprise both direct and indirect effects, as well as immediate and delayed effects; and that any new approval of a GMO should take due account of the potential, cumulative and long-term effects associated with its interaction with other (already released) GMOs and with the environment (Annex II).

The revised directive 2001/18/EC also stresses the importance of respecting ethical principles recognized in a member state. Member states may take into consideration ethical issues when GMOs are deliberately released or placed on the market (Preamble (9)); and Article 29 of the directive states that the Commission, the Parliament, the Council or a member state may seek advice from one of the EU committees on ethical questions relating to general aspects of biotechnology. This part of the directive can be seen as an attempt to address some of the ethical concerns underlying public scepticism about GMOs, although the envisaged consultation is not supposed to affect the administrative procedure outlined by the directive. Presently, it is not at all clear which sort of ethical principles will be taken into account, and what it takes for an ethical principle to be "recognized" in a member state. As we shall demonstrate below, there might be a potential for serious conflict with the general political liberal tenets of the EU regulation.

In the summary of the general European attitude quoted above, "moral doubts" are treated as worries that arise as logically distinct from the consideration of usefulness and risks. Similarly, the directive appears to suggest that "ethical principles" should be applied on top of the determination of whether or not the risk of adverse effects is acceptably low. A somewhat narrow view of morality, or ethics, is at work here: one emphasising that part of ethics concerned with whether or not a certain kind of act or practice in itself is morally wrong.
But ethics also asks how we should evaluate the consequences of acts, all things considered; and it is widely believed that, where everything else is equal, morally right conduct will involve striving to realize the best possible consequences of our actions. If this broader ethical outlook is correct, the assumption in the directive that the basic elements of the approval decision - i.e. the judgement whether or not the risk of adverse effects is acceptably low and the attitude to the uncertainty inherent in this judgement — are without any ethical implications is mistaken. Any decision as to which unwanted effects should be evaluated according to the approval procedure for GM foods and GM crops will, implicitly, introduce an ethical view about which consequences are of importance. Notice, also, that the Precautionary Principle is an ethical principle regarding how the authorities should act in the face of uncertainty (Jensen, 2002).

If public trust in the approval procedure for GMOs is to be restored, it is in our opinion crucial that all the ethically relevant assumptions involved in the procedure should be made transparent - and thus open to public debate. It will be argued in this paper that the revised directive 2001/18/EC fails to make risk assessments, risk management decisions and risk communication more transparent from an ethical point of view. In particular, it is necessary to explicitly state, and hence clarify, the value judgements that are inherent in risk assessments. By "value judgements" we mean judgements implying that, under certain circumstances, something ought to be the case, or something should be preferred to something else. Only when these judgements are made explicit will it be possible to conduct an effective debate about the broader ethical issues involved in the approval of GMOs.

It is generally accepted that the environmental risk assessment of GMOs is a scientific task. The revised EU directive 2001/18/EC itself states that "the environmental risk assessment should be carried out in a scientifically sound and transparent manner based on available scientific and technical data" (Annex IIB). According to the prevailing approach, this means that environmental risk assessment is an exclusively scientific task. Such assessment provides a supposedly objective basis for decisions on whether or not to approve of the release of new GMOs.

We shall argue that this approach is mistaken. Of course, environmental risk assessments are based on scientific and technical data. But these data must fit into a normative framework that is not scientific in nature. This framework stems from the decision problem of whether or not a given application for releasing and 
Making the "Risk Window" transparent

marketing a particular GMO should be approved. The questions the risk assessment is required to answer depend on the criteria for approval. These criteria involve assumptions about what kinds of risk need to be assessed. Hence, an environmental risk assessment views the world through a "risk window" that only makes visible that which has been predefined as a relevant risk; and the size and structure of this window is determined by value judgements about what is considered to be an adverse effect within what is considered the relevant horizon of time and space.

This point is not new. It has been argued for many years by philosophers (Shrader-Frechette, 1985 perhaps being the seminal work) and by social scientists (e.g. Jasanoff, 1990; Wynne, 1996). It has even been clearly acknowledged by an important scientific body like the USA National Research Council (NRC, 1996) and by the World Health Organisation (WHO, 1995). However, it does not appear to have diffused to the field of GMOs.

The value judgements determining the boundaries of risk windows are significant because they limit the information a risk assessment can provide. First, it is an important question to what degree a risk assessment addresses risks that actually concern the public. Second, it always makes sense to ask whether there are any questions that are not addressed by the risk assessment but might affect the public's judgement of whether or not a given GMO is considered worthy of approval or is in fact a good thing. The directive itself appears to acknowledge, as we saw, that some people believe that GM food production in itself is in some way morally unacceptable. However, there also appears to be a widespread perception that GM food production will not bring substantial benefits. And many people worry that large-scale, monopolistic agro-biotech companies operate outside democratic control. None of these issues is addressed directly by the approval procedure.

This paper has two aims. In connection with environmental risk assessment of GMOs we wish, first, to characterize the value judgements comprising the risk window, and second, to demonstrate their importance. Throughout we take a European perspective on the details. However, the general points should be valid for other contexts as well. A greater part of the risk window is determined by the EU directive 2001/18/EC. However, the legislative framework leaves many questions about what, exactly, is to be treated as an adverse effect on the environment open. Nor does the directive state explicitly what level of adverse effect is acceptable.

We begin our analysis by bringing out the political spirit of the directive and the requirements for environmental risk assessment it sets out. We then demonstrate the significance of the risk window through a case study involving the approval of a genetically modified fodder beet in Denmark.

\section{THE LIBERAL FOUNDATION OF APPROVAL}

The overall framework for risk assessment and approval of GMOs is given by the EU directive 2001/18/EC. The directive points out that, in accordance with the Precautionary Principle, member states have an obligation to "ensure that all appropriate measures are taken to avoid adverse effects on human health and the environment which might arise from the deliberate release or the placing on the market of GMOs" (Article 4(1); our emphasis). The objective of the environmental risk assessment is, precisely, "on a case by case basis, to identify and evaluate potential adverse effects of the GMO, either direct and indirect, immediate or delayed, on human health and the environment which the deliberate release or the placing on the market of GMOs may have" (Annex IIA). Apparently, a GMO should be approved if the risk of adverse effects on human health and the environment - as demonstrated by the risk assessment - is acceptably small (the limits of acceptability are not defined). No other considerations should count.

A political liberal foundation (Rawls, 1996) of the regulatory regime is visible here. The guiding idea is that, essentially, the legislation should ensure the freedom and rights of individuals (including industrial companies). The only reason for which the rights and liberties of individuals can be restricted is to prevent harm to other individuals that might result from their exercise. As a fundamental principle, the conduct of an individual may not, against his will, be restricted in his own best interest; nor may it be restricted in order to create benefits to others (Holtug, 2000; Jensen, 2002).

In connection with GMOs, these tenets of political liberalism lead to the idea that legal regulation should protect consumers against harms and reduce the risk of such harms. More precisely, the EU directive protects consumers against harms consisting in adverse health effects. Traditionally, political liberalism restricts protection from harm to a relatively narrow class of welldefined harms. But within the liberal approach, adverse health effects would be regarded as a paradigmatic case of harms from which the legislation should offer protection.

Judgements about whether or not it is in a person's best interest to consume a particular product are left to the 
individual. Consumers can make free choices in an open market. But labelling is important if people are to be able to make choices at all; and information on the qualities of food products is necessary if those choices are to be informed. The exact requirements of GM food labelling by retailers are still being negotiated at the time of writing.

When it comes to general attitudes, political liberalism urges that, although each person has a right to have his attitude respected, even where other people are annoyed by it, no particular attitude should be favored by the law. So, for instance, political liberalism will not prohibit GMOs in order to protect people who believe that GMOs are against the order of nature, and that it therefore is morally wrong to use them; neither will it protect people who believe that GMOs represent a misguided political goal for agriculture. Such people should be free to choose not to use GMO products for themselves, but they must agree to live in a society where, as long as these products are not harmful, others can produce, sell, buy and consume them if they wish.

From a political liberal point of view, then, the overall acceptability of GMOs to consumers should manifest itself though their choice of products. It is very important to make this clear, because, as we saw in the introduction, an important factor influencing the acceptability of GMOs to many people is that they should be "useful", i.e. represent substantial benefits either to consumers or to society in general. But this question is not addressed by the approval system, let alone the risk assessment.

The directive 2001/18/EC also protects the environment against adverse effects. Traditional political liberalism (e.g. Mill, 1859) takes an anthropocentric view of nature, according to which, in the last resort, it is for the sake of human benefit, either now or in the future, that we should protect the environment. (However, individual animals are often considered worthy of protection in their own right). We should, then, avoid effects on the environment that might threaten human interests. There are several competing views about what interests, exactly, humans have in nature. It would be fully in the liberal spirit, however, to treat a rather narrow range of human interests relating to nature as worthy of protection - e.g. to ensure that natural resources are used in a sustainable way or that humans are protected against adverse environmental health effects.

The directive 2001/18/EC can nevertheless be interpreted on the basis that the environment is worthy of protection in its own right, irrespective of human interests. In addition to the human-interest point of view, other life forms are entitled to respect, and we should protect these life forms for their own sake. This nonanthropocentric approach is a departure from traditional political liberalism, but it is not incompatible with the liberal framework, particularly if the range of adverse effects to the environment covered is kept rather narrow. So the central question is: what exactly should count as an adverse effect on the environment, according to a nonanthropocentric view? There are several competing answers to this question as well.

One answer, known as "biocentrism", claims that in principle all living individuals have an equal right to have their interests fulfilled or protected. A second answer, known as "ecocentrism", sees humans as members of a biotic community, consisting of animals, plants, soil and water, and insists that we should avoid disturbing the stability and integrity of this community. A third answer claims that we should not interfere with the remaining natural areas. On this view, farmland does not deserve to be protected in its own right, although certain farm practices might still be wrong because they affect, and hence interfere with, "wild" nature.

As they stand, these views are very general. It is hard to assess their implications. Considerable clarification would be required before we could say, for example, whether, on one or other of the views, gene-spread from GMOs is a problem in itself; similarly, there may well be disagreement over whether or not gene-spread in itself is an adverse effect to human interests. For these reasons, the notion of an "adverse effect" on the environment seems to be more complex than that of an adverse effect on human health. It remains true, however, that the characterisation of relevant adverse effects on the environment - and the identification of connected environmental hazards - is of the utmost importance in the design of risk assessment procedures.

To sum up, the normative objective of regulation is to avoid adverse effects on human health and the environment. This objective is to be achieved by approving only those GMOs involving an acceptably small risk of such adverse effects (although the limits of acceptability are not defined). The task of an environmental risk assessment is to provide information on the basis of which it is possible to judge whether or not the risk of adverse effects of a particular GMO is acceptably small. In the remaining part of this paper we shall concentrate on risks to the environment.

Before we carry on, we shall briefly compare the political liberal foundation of the EU regulation with a set of ethical principles for genetic engineering, recently 
adopted by the Danish Government (Danish Ministry of Trade and Industry, 2000). They are:

(1) Economic and qualitative benefits.

(2) Autonomy, dignity, integrity and vulnerability.

(3) Just distribution of benefits and burdens.

(4) Codetermination and openness.

Roughly, (2) implies protection of man, animals and nature. This is not in conflict with political liberalism, although of course there can be disagreement about how rigid the protection should be. Similarly, (4) does not conflict with political liberalism, even though present practice might not fully incorporate it.

However, (1) requires that technologies represent substantial benefits, not just economic ones, as a precondition of accepting possible risks. This implies that the authorities, rather then the market, should evaluate the potential benefits of a technology and determine, on behalf of everyone, whether or not it should be used. This step departs seriously from the liberal underpinnings of technology regulation in the western world. Is it feasible to allow such a departure for one type of technology (GMOs) only, or should it be extended to all technologies?

Likewise, (3) requires that GMOs should not conflict with efforts to create a just distribution of benefits and burdens. However, extending the approval procedure for a specific technology in this way would also create problems. One is that, from a legal point of view, it seems wrong to include such highly general matters in the approval procedure for a particular technology application. If monopolies in general are unwanted, for instance, they should be controlled directly by legislation such as, e.g., the Monopolies and Restrictive Practice Act, or by regulatory bodies such as, e.g., the Monopolies and Mergers Commission, and not through an approval procedure for specific technologies. The approval procedure should not distinguish between applications from very big companies and small companies. Similarly, if a general political goal in society is unpopular, it should be changed by political means, not through the approval procedure for specific technologies.

\section{RISK ASSESSMENT ACCORDING TO THE DIRECTIVE}

A risk assessment must take, as its point of departure, a definition of the situation in which some specified risk is to be assessed. As for the environmental risk assessment of GMOs, we have already described how the objective of the EU directive 2001/18/EC is defined to involve the identification and evaluation of any potential adverse effects on human health and the environment which the deliberate release of a particular GMO may have at some specific point in time.

The directive lists six steps in environmental risk assessment (Annex C2) that appear to be derived from a framework developed by the Food and Agriculture Organisation of the United Nations (FAO) and the World Health Organisation (WHO) for risk assessment in the food standards area (FAO, 1997):

(1) Identification of characteristics which may cause adverse effects.

(2) Evaluation of the potential consequences of each adverse effect, if it occurs.

(3) Evaluation of the likelihood of the occurrence of each identified potential adverse effect.

(4) Estimation of the risk posed by each identified characteristic of the GMO(s).

(5) Application of management strategies for risks from the deliberate release or marketing of $\operatorname{GMO}(\mathrm{s})$.

(6) Determination of the overall risk of the GMO(s).

Thus approached, environmental risk assessment begins with hazard identification. In the context of GMOs, a hazard is defined as a characteristic of the GMO which may cause adverse effects. However, although hazards must be identified with an eye on effects that are considered adverse, it is not immediately apparent how hazards are to be identified in a systematic way.

To identify a hazard we need to know what kinds of adverse effect should be avoided. We know these effects will have to be on human health or the environment; and the directive gives the following examples of possible adverse effects of GMOs (Annex IIC2.1):

- disease to humans including allergenic or toxic effects;

- disease to animals and plants including toxic, and where appropriate, allergenic effects;

- effects on the dynamics of populations of species in the receiving environment and the genetic diversity of each of these populations;

- altered susceptibility to pathogens facilitating the dissemination of infectious diseases and/or creating new reservoirs or vectors;

- compromising prophylactic or therapeutic medical, veterinary, or plant protection treatments, for example by transfer of genes conferring resistance to antibiotics used in human or veterinary medicine;

- effects on biogeochemistry (biogeochemical cycles), particularly carbon and nitrogen recycling through changes in soil decomposition of organic material.

The adverse effects on human health are relatively clear; they include diseases, altered susceptibility to diseases 
and compromised medical treatment. The adverse effects on the environment are somewhat harder to grasp. One group concerns diseases to animals or plants, altered susceptibility to diseases, and compromized veterinary or plant protection treatment. This group clearly covers farm animals and crops, but it is not clear to what extent it also covers wild animals or plants. Another group concerns effects on the dynamics and genetic diversity of populations in the environment. However, it is not clear exactly what kinds of effect would be considered adverse here. Would any effect on population dynamics or genetic diversity be adverse, or are only some effects of this kind to count? Notice that, according to the view that humans ought not to interfere with natural areas, any effect outside the cultivated areas would be adverse; whereas according to the anthropocentric view of nature, only such effects that violate human interests would be considered adverse. The last group comprises effects on biogeochemical cycles, but again it is unclear whether any such effect would be considered adverse or only certain types of such effect.

The limitations in space and time within which the possible adverse effects should be examined are left open. In any given case, it must be decided which areas the risk assessment should cover. Similarly, it must be decided how far into the future the assessment should reach, since there may be a substantial time lag between the introduction of a GMO and the emergence of environmental problems related to this. As we know, the revised directive 2001/18/EC stresses that the risk assessment must "identify and evaluate potential adverse effects of the GMO, either direct and indirect, immediate or delayed, on human health and the environment which the deliberate release or the placing on the market of GMOs may have" (Annex IIA). How far should the assessment of indirect effects reach?

GMOs differ greatly in their long-term effects. In terms of gene-spread, genetically modified herbicide tolerant cultivated beet (see the case study below) seems to be a low risk crop when grown in a one-year rotation system. This is because it only flowers during the second growing season and because the beets compete poorly with other plant species. When it comes to trees, accumulated long-term effects might take half a century or more to manifest themselves; and a monitoring programme may require more than 10 generations of trees to acquire information on critical parameters used for predictions (Tømmerås et al., 1996). It can be seen, then, that if the risk assessment were restricted to consequences occurring within the next 10-20 years, it might be difficult to identify any relevant adverse effects to the environment from the release of genetically modified trees.

The revised directive 2001/18/EC also points out that risk assessments should take "due account of the accumulated long-term effects associated with the interaction with other GMOs and the environment" (Preamble (19)). The accumulated long-term effects should also form a "compulsory part of the monitoring plan" (Preamble (20)). The accumulated long-term effects mentioned here are "the accumulated effects of all consents on natural flora, other crops, soil fertility, soil degradation or organic material, the food chain, biological diversity, human health, and resistance problems in relation to antibiotics (Annex II)." Clearly, the intention at this point is to insist that the relevant risk to assess when approving a GMO is its effect on the total risk of adverse effects, not the risk of that particular GMO considered in isolation. Equally clearly, a total risk of this kind will be very hard to assess.

Finally, the directive mentions the following examples of mechanisms through which adverse effects may occur (Annex C2.1):

- the spread of the GMO(s) in the environment;

- the transfer of the inserted genetic material to other organisms, or the same organism whether genetically modified or not;

- phenotypic and genetic instability;

- interactions with other organisms;

- changes in management, including, where applicable, in agricultural practices.

We should expect risk assessments of GMOs to cover these mechanisms.

\section{THE FAMILIARITY PRINCIPLE AND DECISION CRITERIA}

The directive 2001/18/EC sets out the conclusion of the risk assessment more precisely by defining a standard of comparison: "identified characteristics of the GMO and its use which have the potential to cause adverse effects should be compared to those presented by the nonmodified organism from which it is derived and its use under corresponding situations" (Annex IIB).

This passage presses into service the so-called Familiarity Principle, first introduced in an OECD report (OECD, 1993). The idea is that the task of the risk assessment is to assess the extent to which replacement of the non-modified organism by the GMO gives rise to additional adverse affects. It is noticeable that any adverse effect the non-modified organism may have 
(measured in contrast with non-use or some other standard) is not under assessment.

Originally, the Familiarity Principle was introduced as a means to focus the risk assessment so as to ensure optimal use of already existing knowledge (OECD, 1993, pp. 8, 28). However, the directive 2001/18/EC appears to elevate it to a decision criterion. Accordingly, if the risk assessment concludes that the GMO does not give rise to additional adverse effects, the GMO should be approved. From a liberal point of view, the status quo has gained a prescriptive right, even if it appears harmful in certain respects.

This decision criterion has been contested, though. For instance, Austria uses organic agriculture as its standard of comparison; and other countries have expressed reservations as well (see the overview in Lewidow and Carr, 2000).

It may be uncertain how a particular GMO will be used, since the use will depend on the huge number of factors involved in determining the farmer's choice of crops in the years to come. Furthermore, in connection with any actual use of a GMO there may not be a corresponding use of the non-modified organism to compare - this would be the case, for instance, where the use of the GMO is more or less widespread than the actual use of the non-modified organism. Presumably, the directive implies that use of the GMO should be compared (where necessary) with hypothetical use of the non-modified organism under similar circumstances.

Lastly, the revised directive 2001/18/EC explicitly mentions a number of issues that should be addressed in the conclusion of the risk assessment. In the case of genetically modified higher plants (GMHPs, i.e. vascular plants), they are (Annex II, D2):

(1) Likelihood of the GMHP becoming more persistent than the recipient or parental plants in agricultural habitats or more invasive in natural habitats.

(2) Any selective advantage or disadvantage conferred to the GMHP.

(3) Potential for gene transfer to the same or other sexually compatible plant species under conditions of planting the GMHP and any selective advantage or disadvantage conferred to those plant species.

(4) Potential immediate and/or delayed environmental impact resulting from direct and indirect interactions between the GMHP and target organisms, such as predators, parasitoids, and pathogens (if applicable).

(5) Possible immediate and/or delayed environmental impact resulting from direct and indirect interactions of the GMHP with non-target organisms, (also taking into account organisms which interact with target organisms), including impact on population levels of competitors, herbivores, symbionts (where applicable), parasites and pathogens.

(6) Possible immediate and/or delayed effects on human health resulting from potential direct and indirect interactions of the GMHP and persons working with, coming into contact with or in the vicinity of the GMHP release(s).

(7) Possible immediate and/or delayed effects on animal health and consequences for the feed/food chain resulting from consumption of the GMO and any products derived from it, if it is intended to be used as animal feed.

(8) Possible immediate and/or delayed effects on biogeochemical processes resulting from potential direct and indirect interactions of the GMO and target and non-target organisms in the vicinity of the GMO release(s).

(9) Possible immediate and/or delayed, direct and indirect environmental impacts of the specific cultivation, management and harvesting techniques used for the GMHP where these are different from those used for non-GMHPs.

The directive does not explicitly state how much greater the adverse effects (as compared to the non-GMO) need to be before they become unacceptable. As a consequence, it is unclear whether any additional effects would be unacceptably adverse, or whether additional adverse effects would be acceptable below a certain threshold. This list therefore fails to make precise the view of nature that should guide approval decisions.

\section{A CASE STUDY IN ENVIRONMENTAL RISK ASSESSMENT}

To illustrate the role of value judgements in risk assessment, we shall describe the environmental component of a risk assessment of glyphosate resistant fodder beets (Beta vulgaris L. ssp. vulgaris) conducted in Denmark. The assessment in this case study was performed under the now superseded directive 90/220/ EEC. However, we shall keep the present directive in the foreground of the discussion, noting, of course, any differences between the directives that are relevant to the case.

In 1997 the competent authority in Denmark - the Danish Environmental Protection Agency (EPA) received an application (C/DK/97/01) to market genetically modified glyphosate tolerant fodder beet. The EPA asked the National Forest and Nature Agency (NFNA), the Danish Plant Directorate (PD) and the 
Danish Veterinary and Food Administration (VFA) for scientific advice on the potential effects such beet would have on the environment, agriculture and health. A summary of the notification information was also circulated to 45 research centres, relevant organisations, interest groups and authorities, and a hearing was then held. The final risk assessment, prepared by the EPA, was based on scientific evaluations and answers from the hearing, together with the notification and other information (EPA, 1997).

The NFNA's risk assessment (1997) focuses on "the behaviour of the genetically modified fodder beet outside cultivated areas" (EPA, 1997, p. 2). It states: "Experiments show that the genetically modified fodder beet is not different from the traditionally grown fodder beet in terms of flowering, plant height, size of root and stem, size of leaves, seed production [...] and ability to germinate. Furthermore no differences were observed in tolerance to cold and ability to establish on sea shores" (p. 2). It also states that "the new trait has not changed the possibilities for hybridization with wild relatives. Beta maritima is the only wild growing relative in Denmark, and it is estimated that the spread of the glyphosate tolerance gene to Beta maritima will be without ecological consequences since glyphosate is not used close to sea shores" (p. 2).

The NFNA assessment concludes that "compared with the traditionally improved fodder beet the genetically modified fodder beet seems not to be different as far as abilities to compete, establish and survive during winter are concerned" (EPA, 1997, p. 3), and that "no ecological effects are expected" (p. 3).

The PD (1997) estimated that "problems with seed contamination can be handled in the seed producing areas, and that glyphosate tolerant weed beets will only occur after a very long period. To prevent a seed bank of glyphosate tolerant weed beets, weed beets and beets flowering in the fields should be controlled" (EPA, 1997, p. 3). It also advised that: "Due to information on chemical composition and nutritional values it is expected that the genetically modified fodder beet are not different from traditionally improved cultivars as far as fodder quality is concerned" (p. 3). The PD concluded that GM fodder beet "is of no risk for agriculture in Denmark" (p. 3).

We are here concerned with the environmental aspect of the risk assessment, so we shall not discuss the VFA assessment of adverse health effects. However, the EPA itself initiated a project in which herbicide use in GM herbicide resistant crops was modelled. Using computer simulations, it concluded: "The simulation model showed reductions in amount and frequencies of herbicide use when herbicide resistant beets replaced traditionally improved beets in crop rotation" (EPA, 1997, p. 3).

The EPA's overall conclusion was that: "The product can be placed on the market without risk to human health and the environment" (EPA, 1997, p. 3).

It is not our intention to discuss the soundness these conclusions in themselves. Our aim is rather to ask: What are the acceptance criteria for the decision? What issues does the risk assessment focus on, and how do these relate to the acceptance criteria? What kinds of question are not raised by the risk assessment? How do the data support the estimates, and what is the reasoning leading from the premises to the conclusion? None of these questions is addressed directly in the risk assessments. This makes it very hard for observers to interpret both the assessments themselves and the decision based on them. In the following section we shall attempt to reconstruct answers to these questions.

\section{RECONSTRUCTING THE "RISK WINDOW" IN THE CASE STUDY}

Let us begin by taking a more detailed look at the risk assessment in our case study. We can start by noting that no explicit approval criteria are stated, let alone argued for, in this assessment; and that it is impossible to safely infer any such criteria from this single assessment and decision. Clearly, however, transparency would require the criteria of approval to be openly presented and discussed.

We now know that the impetus behind risk assessment is liberal in character and concentrates on specific, more or less well defined adverse effects. Still, the adverse effects studied in this risk assessment are nowhere listed or indicated. Moreover, the conclusions of the scientific advisors appear to rely heavily upon the Familiarity Principle, and thus the majority of the studies take the existing level of effects from non-modified beet as the standard of comparison. There is, however, no discussion of the implications and limitations of this reliance on the Familiarity Principle.

Consider the NFNA's risk assessment. It prioritizes the question: "Does the inserted gene result in a different behaviour of the GM fodder beet, in comparison with the traditionally improved fodder beet?" And the evidence appears to show that GM beet has no competitive advantage over traditionally improved beet in areas where glyphosate is not likely to be used. 
Making the "Risk Window" transparent

One scenario considered is that the GM beet might take root outside the field. It is concluded that this would have no ecological consequences. This means that spread of the GM beet beyond the field is not in itself considered an adverse effect: it would be adverse only if the GM beet was more competitive than the traditionally cultivated beet.

Another scenario considered involves the spread of the transgene to wild relatives. The NFNA concedes that it is possible that the transgene will spread to the wild relative, Beta vulgaris ssp. maritima, but it indicates that this is not an adverse effect because such spread will only give competitive advantage in the extreme unlikely event that glyphosate is used in seashore areas.

The underlying risk window can now be reconstructed. The spread of the transgene, either by the GMO itself, or by gene flow, does not in itself represent an adverse effect. It is environmental impacts connected with this spread - that is, changes in the dynamics of the population of the species connected with GM-based competitive advantage — that would be adverse. However, there is no account of why, exactly, these scenarios, and no others, have been chosen for study.

Note that the approval procedure, strictly speaking, only comprises adverse effects on non-cultivated areas in Denmark (see further below). Whereas the limitation to non-cultivated areas seemed to follow from the previous directive 90/220/EEC, the limitation to Denmark appears to be an upshot of the administrative procedure. The Danish assessment was later to be commented on by the competent authorities of the other EU countries. However, this procedure is not explicitly explained in the risk assessment.

According to new directive 2001/18/EC, indirect effects should also be assessed. However, this requirement did not appear in the previous directive 90/220/ EEC, and there appears to be no assessment of such indirect effects. Equally, there appears to be no assessment of effects on biogeochemical cycles.

Let us now turn to the risk assessment of effects on agriculture itself. An obvious effect of this sort is that, if gene flow transfers the glyphosate resistance trait to weed beets, farmers may find that they can no longer use glyphosate herbicide for (post-emergence) weed control in beet crops. The likelihood of this happening will depend on agricultural practice.

However, management practice does not fall within the scope of the previous directive 90/220/EEC. Therefore, even though the risk of such adverse effects is recognised in the risk assessment, these effects are not strictly speaking part of the approval procedure. It follows that the assessment can only recommend a certain practice to prevent glyphosate tolerant weed beets; it cannot make strict requirements for approval. In this respect, things seemed to have changed under the new directive 2001/18/EC, where management practice is an explicit part of the risk assessment.

Another potential adverse effect - at least, so far as seed producers wishing to guarantee a GMO free product are concerned - would be gene flow to organically produced beet seed. But again, this eventuality appears to be interpreted as outside the scope of directive 90/220/ EEC. Consequently, it is not part of the risk window and it is not mentioned in the risk assessment. It is not entirely clear what directive 2001/18/EC implies on this question. Probably, the matter must be regulated by other means e.g. through protection borders, an upper limit for the concentration of GM contaminants in organic products, ordinary liability regulation and the like. In any case, a clear statement that this question (which has been the object of considerable public attention) simply fell outside the scope of the risk assessment would have greatly increased the transparency of the risk assessment.

Under directive 90/220/EEC, risk assessors were not required to simulate effects on herbicide use in the way undertaken by the EPA. It seems likely that the EPA performed a simulation primarily because the Danish Government has a general policy of reducing herbicide use. For this political reason, if the introduction of the GM fodder beet were to result in an increased use of herbicides, that increase would be counted as an unwanted effect.

It is striking that evaluation of the data on which this risk assessment is based is poorly described. The EPA (1997) summarises the conclusions of the scientific advisors (NFNA, 1997; PD, 1997), but it does not subject them to independent evaluation, i.e. assess the validity and reliability of the conclusions given the experiments performed. It is true that the scientific advisors evaluate the data of the quoted research studies to some extent. However, this evaluation is described neither thoroughly nor systematically.

Equally strikingly, several of the cited studies looked, not at the fodder beet for which the applicant was seeking approval, but sugar beet - a crop in which a different gene sequence codes for glyphosate tolerance. The reliability of the necessary extrapolations is not described, however. Nor do the scientific advisors evaluate the experimental design, the influence of geographic location or the statistical methods on which the conclusion of "no significant difference" is based; and it is impossible to obtain an impression of the 
variation within the experiments where such "no significant differences" were reported. The assessment therefore does not give the public an opportunity to assess the soundness of the studies upon which the risk assessments are based.

It hardly needs saying that it is important that the public know how reliable the results of a risk assessment are, and where uncertainties remain. This information is also necessary if the Precautionary Principle is to be applied. The Commission's own Communication on the Precautionary Principle clearly states that there should be an evaluation of the reliability of a risk assessment and its components, and an indication of the remaining uncertainty (CEC, 2000c). This is deemed necessary because the Precautionary Principle is to be applied in cases where "there are reasonable grounds for concern that potential hazards may affect the environment or human, animal or plant health" (p. 9), but where the insufficient or inconclusive nature of the scientific data prevents the risk from being "fully demonstrated or quantified or its effects determined" with certainty (p. 13).

\section{CONCLUSION}

We have demonstrated that environmental risk assessment is not an exclusively scientific task. Such assessment is based on a number of value judgements, and together these form what we call the "risk window", i.e. the demarcation in space and time of the possible adverse effects to be assessed, and the choice of hazards to be assessed for possible adverse effects. This demarcation is a necessary precondition of the scientific part of the risk assessment, which consists in an estimate of the extent of the adverse effects, should they occur, and an estimate of the likelihood of their occurrence.

We have attempted to describe the content of the risk window prescribed in the new directive 2001/18/EC, and to identify some of the questions to which it gives rise. Even though the new directive has a wider risk window than the directive 90/220/EEC, the general point remains: there is still a risk window, and it still limits the information the risk assessment is able to provide.

In the case study, we showed how the risk window works in the assessment of GM fodder beet. We highlighted the lack of transparency in the risk assessment. To restore public trust in the approval procedure for GMOs, the elements of the procedure need to be made far more transparent to the public. In particular, the value judgements underlying the regulation and particularly delimiting the risk assessment need to be made explicit; and the limitations of available data, and any uncertainties they give rise to, ought to be made clear. The public is unlikely to believe that science is able to answer all questions about GMOs. Hence, any attempt to conceal the limitations of scientific knowledge is bound to create distrust. The addressal of scientific uncertainty is also required if the Precautionary Principle is to be applied.

Transparency in the approval procedure will allow effective dialogue between authorities, risk assessors, politicians and the public to take place. The central question is whether the GMO approval procedure actually addresses the worries of the public, and it is hard to see how we can answer this question without an open discussion of the ethical and value-related issues involved in the use of GMOs. To take part in a discussion of this sort, risk assessors and public authorities will need to develop a better understanding of the values and attitudes underlying public scepticism towards GMOs. As the discussion of the Danish Government Statement on ethical principles revealed, many issues surrounding GMOs lie outside the scope of what risk assessment can evaluate.

It is precisely because of the controversial nature of these other issues that the liberal tradition wants to leave as many choices as possible to the individual. The liberal approach implies that all technologies without unacceptable risk of adverse effects should be approved. People should be free to choose not to use GM products, but they must also be content to live in a society in which these products are made available to people who want them.

On the other hand, the demand for stricter regulation of GMOs might stem from fact that, in this area, people do not trust the market to bring about a state of affairs that generally improves welfare and respects ethical values. Many people appear to think that powerful international companies dominate the world market in GMOs, and that presently there is no democratic means of controlling developments to ensure that free choice on the market is a real option.

\section{ACKNOWLEDGEMENTS}

We should like to thank Folmer Eriksen, Poul Harremoës, Thure Hauser, Vibeke Meyer, Jan Pedersen, Svend Pedersen, Gitte S. Poulsen, Birgitte Rasmussen, Peter Schaarup, Morten Strandberg and Geir Tveit and for useful comments and suggestions. We have special debts to Paul Robinson. 
Making the "Risk Window" transparent

\section{REFERENCES}

Biotechnology and the European Public Concerted Action Group (BEPCAG) (1997) Europe ambivalent on biotechnology. Nature 387: 845-847

CEC (1990) Council Directive 90/220/EEC of 23 April 1990 on the deliberate release into the environment of genetically modified organisms

CEC (1992) Opinions of Europeans on Biotechnology in 1991. Eurobarometer 35.1. Science Museum, London

CEC (1993) Biotechnology and Genetic Engineering: What Europeans Think about it in 1993. Eurobarometer 39.1. CEC, Brussels

CEC (1997) European Opinions on Modern Biotechnology. Eurobarometer 46.1. CEC, Brussels

CEC (2000a) The Europeans and Biotechnology. Eurobarometer 52.1. CEC, Brussels

CEC (2000b) Press Release of 13 July 2000. European Commission: press and information service IP/00/778

CEC (2000c) Communication from the Commission on the Precautionary Principle. CEC, Brussels

CEC (2001) Directive 2001/18/EC of the European Parliament and of the Council of 12 March 2001 on the deliberate release into the environment of genetically modified organisms and repealing Council Directive 90/220/EEC - Commission Declaration

Danish Ministry of Trade and Industry, The (2000) The Danish Government Statement on Ethics and Genetic Engineering. Copenhagen

EPA (1997) Notification C/DK/97/01. Summary of the evaluation carried out by the Danish competent authority

FAO (1997) Risk management and food safety. Report of a joint FAO/WHO consultation Rome, Italy, 27 to 31 January 1997. FAO Food and Nutrition Paper 65

Holtug N (2000) The harm principle and genetically modified food. J. Agr. Environ. Ethic 14: 169-178

Jasanoff S (1990) The Fifth Branch: Science Advisers as Policymakers. Harvard University Press, Cambridge
Jensen KK (2002) The Moral Foundation of the Precautionary Principle. J. Agr. Environ. Ethic 15: 39-55

Levidow L and Carr S (eds.) (2000) Precautionary Regulation: GM Crops in the European Union, J. Risk Res., Special Issue 3 (3)

Mill JS (1859) On Liberty. In Mill JS, ed, Utilitarianism, On Liberty, Considerations on Representative Government London Dent, 1993, pp 69-185

NFNA (1997) Vedr. anmeldelse af foderroe (Beta vulgaris L. ssp. vulgaris) til markedsføring, i henhold til del C, artikel 12(3) i Direktiv 90/220/EØF. Skov- og Naturstyrelsen.

NRC (1996) Understanding Risk: Informing Decisions in a Democratic Society. Academy Press, Washington D.C.

OECD (1993) Safety Considerations for Biotechnology: ScaleUp of Crop Plants. Publications Service, OECD, Paris

PD (1997) Vedr.: Vurdering af anmeldelse om markedsføring af en genetisk modificeret foderroe (C/DK/97/01). Plantedirektoratet.

Rawls J (1993) Political Liberalism. Columbia University Press, New York

Shrader-Frechette KS (1985) Risk Analysis and Scientific Method, Reidel, Dordrecht

Tømmerås BÅ, Johnsen Ø, Skrøppa T, Hindar K, Holten J, Tufto J (1996) Long-term environmental impacts of release of transgenic Norway spruce (Picea abies). Trondheim: NINA/NIKU, Foundation for Nature Research and Cultural Heritage Research

VFA (1997) Vedr. vurdering fra Instituttet for Toksikologi af ansøgning C/DK/97/01 om markedsføring af gensplejset foderroe A5/15. Veterinær- og Fødevaredirektoratet

WHO (1995) Application of Risk Analysis to Food Standards Issues, Report of the Joint FAO/WHO Expert Consultation, 13-17 March 1995, Geneva, Switzerland

Wynne B (1996) May the Sheep Safely Graze? A Reflexive View on the Expert-Lay Knowledge Divide. In Lash S, Szerszynski B and Wynne B, eds, Risk, Environment and Modernity. Towards a new Modernity. Sage, London, pp 44-83 